determined in cases where the application of an over-voltage or an over-current is inconvenient.

The communication is published by permission of the Director General of Research of the National Coal Board, and the views expressed herein are those of the author and do not necessarily represent official opinions of the Board.

National Coal Board,

Mining Research Establishment, Isleworth, Middlesex.

\section{$\gamma$-Spectrometry compensated for the Compton Effect}

Perrson et al..$^{-3}$ proposed an efficient technique for obtaining net photopeaks in $\gamma$-spectrometry by subtracting the Compton continuum of the NaI(Tl) detector by means of an anthracene scintillator. The photoelectric effect in the latter is indeed negligible and gives rise to the Compton effect only. After equalization for pulse height and counting-rate, net photopeaks are thus obtained.

To minimize counting losses, the detection efficiency of both detectors, in the Compton region, should be approximately the same. This requires equal diameters of the scintillators. The cost of the anthracene detector thus becomes quite high when large $\mathrm{NaI}(\mathrm{Tl})$ crystals are used. It appeared, however, that a plastic seintillator (Nuclear Enterprises $N E 102$ ) is equally suitable for this purpose, resulting in a detector cost reduction by a factor of approximately 50 .

The detection efficiency of this plastic is about 60 per cent in comparison with the anthracene, whereas the pulse height is about 67 per cent.

Uncompensated and compensated spectra of cobalt-60, using a 3 in. $\times 3$ in. $\mathrm{NaI}(\mathrm{Tl})$ and 3 in. $\times$ $\frac{1}{2}$ in. anthracene crystal or a 3 in. $\times \frac{1}{2}$ in. NE 102 plastic scintillator, are given in Fig. 1. From this it appears that an even better compensation for the Compton edge is obtained with the latter. For the spectrum compensated with the plastic scintillator, the detectors were at an angle of $90^{\circ}$ and mounted in lead collimators.

When mounted at an angle of $180^{\circ}$, the back scatter is indeed still quite important and extends up to the $500-\mathrm{KeV}$. region, whereas at an angle of $90^{\circ}$ a reduction in back scatter by a factor 3 is obtained.

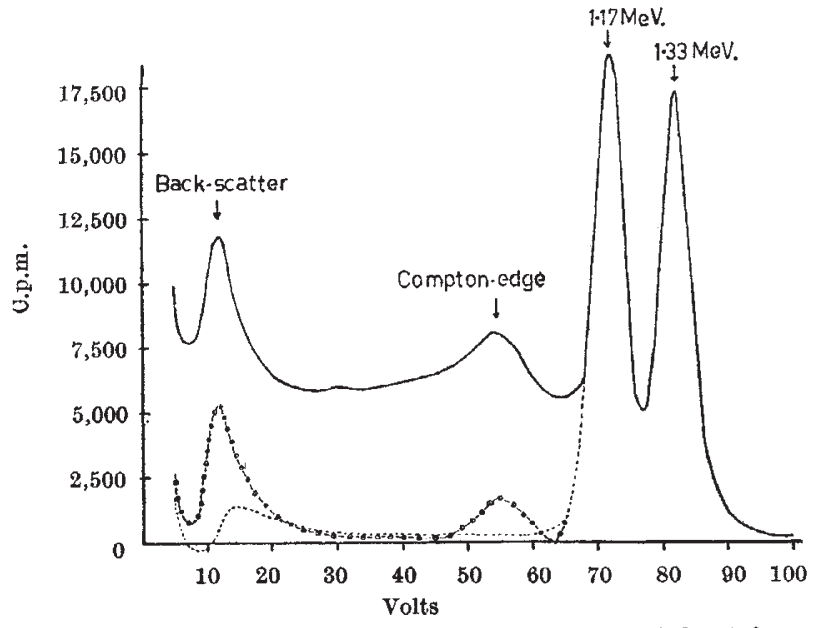

Fig. 1. Spectrum of cobalt-60. Uncompensated $\left(180^{\circ}\right.$

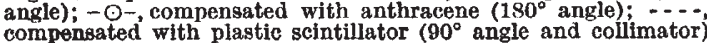

The detection efficiency, caused by the lead collimator, is reduced by 20 per cent only.

This technique appeared to be more efficient than the use of a lead absorber before the anthracene crystal as recommended by Peirson et al. ${ }^{4}$.

\section{De Soete}

J. HosTE

Laboratory for Analytical Chemistry, University of Ghent.

1 Peirson, D. H., Nature, 173, 990 (1954).

${ }^{2}$ Peirson, D. H., Brit. J. App. Phys., 6, 444 (1955).

${ }^{3}$ Peirson, D. H., and Iredale, P., Unesc. Conf. Paris (1957).

4 Peirson, D. H., and Iredale, P., Brit. J. App. Phys., 8, 422 (1957)

\section{GEOLOGY}

\section{Age of Deglaciation in the Ruwenzori Range, Uganda}

THE massive fault-block of the Ruwenzori Mountains, which lies on the axis of the Western Rift between Uganda and the Congo, is the wettest of the high mountain areas in East Africa. For that reason it has more glaciers at present and has been more extensively glaciated in the past than any of the other tropical African mountains. Although relative ages have been estimated ${ }^{1,2}$, no absolute dates have been published for prehistoric glacial events in this or any other tropical African mountain area.

During July of $1960 \mathrm{Mr}$. Jonathan Richardson, Mr. Robert Kendall and I collected cores from the sediment that had accumulated in glacial lakes at a variety of altitudes on the Uganda side of the Ruwenzori Range. Much of the sediment was fossiliferous and organic enough to permit radiocarbon dating, and an analysis of one sample by Isotopes, Inc., of Westwood, New Jersey, has provided the first absolute date of a major glacial event in East. Africa.

The lowest Ruwenzori moraines are in the Mobuku Valley, where they extend down to $2,100 \mathrm{~m}$. near Ibanda. Lateral moraines at slightly higher altitudes occupy the smaller valleys of the mountains. All these moraines are several orders of magnitude larger than any between them and the present glacier termini. Presumably they have been built up during several glaciations; but good exposures are rare and no evidence of interglacial episodes has come to light.

No lakes are to be found close to the lower ends of the low moraines, but one does lie at the junction of the Mobuku River lateral moraine system with that of its principal tributary, the Bujuku River. This is Mahoma Lake (lat. $0^{\circ} 21^{\prime}$ N., long. $29^{\circ} 58^{\prime}$ E.) at an altitude of $3,000 \mathrm{~m}$. Its shape, size, depth and relation to the associated moraines all suggest that it occupies a kettle and there is no evidence of a glacial still-stand between it and the lowest morainos in the valley.

We raised a core almost $6 \mathrm{~m}$. long from the mud under $9.5 \mathrm{~m}$. of water in Mahoma Lake. The drilling operation ceased when the borer entered sandy gravel with pieces of stone more than $4 \mathrm{~cm}$. in diameter and the section appeared to be complete. The lowest $0.4 \mathrm{~m}$. of sediment consisted of coarsely graded grey clay, silt and fine sand. The change to organic sediment began rather sharply at a depth of $5.4 \mathrm{~m}$. and was complete within $0.2 \mathrm{~m}$. The organic lake mud consisted very largely of algal remains and was uniform in gross appearance to the top of the section.

The grey inorganic material looks as if it had been laid down very rapidly while the glacier was still 